Research Article

\title{
Damping Properties and Microstructure Analysis of Microbial Consolidated Rubber Sand
}

\author{
Pei Li $i^{1,2}$ \\ ${ }^{1}$ CCCC First Harbor Engineering Company Ltd., Tianjin, China \\ ${ }^{2}$ Tianjin Port Engineering Institute Co. Ltd. of CCCC First Harbor Engineering Co.,Ltd., Tianjin, China
}

Correspondence should be addressed to Pei Li; 512015321@qq.com

Received 8 May 2021; Revised 18 June 2021; Accepted 11 August 2021; Published 29 September 2021

Academic Editor: Ling Fan

Copyright (C) 2021 Pei Li. This is an open access article distributed under the Creative Commons Attribution License, which permits unrestricted use, distribution, and reproduction in any medium, provided the original work is properly cited.

Up to now, there are few reports on the application of microbial-induced calcium carbonate precipitation (MICP) consolidated rubber sand. By means of uniaxial or cyclic loading test and SEM test, the consolidation effect of rubber sand samples with different rubber particle content after MICP consolidation is tested and analyzed. The results show that MICP is not affected by the amount of rubber particles; rubber particles improve the compressive strength and deformation ability of consolidated rubber sand samples and significantly enhance the damping ratio, resistance to deformation, and energy dissipation ability of consolidated rubber sand samples. Rubber sand after MICP consolidation is a good shock damping material. The conclusion of this paper provides reference data for the application of microbial-induced calcium carbonate precipitation consolidated rubber sand.

\section{Introduction}

Earthquake, mechanical vibration may lead to the vibration destruction of construction $[1,2]$, and waste tyres will cause serious environmental pollution. It is one of the main ways to recycle waste tyres by crushing them into rubber particles and then used in civil engineering. Mixtures of small-sized rubber and sand have important applications in geotechnical engineering [3, 4], and a study has shown that rubber sand is a suitable and cheap damping material: Tsang [5] studied using rubber sand to replace foundation soil; when the maximum dynamic shear modulus of rubber sand cushion is $7.5 \mathrm{MPa}$ and the thickness is $10 \mathrm{~m}$, the peak value of horizontal acceleration of superstructure is $75 \%$ lower than that before replacement, and the peak value of vertical acceleration is $90 \%$ lower than that before replacement; Panah and Khoshay [6] filled the rubber sand into the pipe pile, and the lateral static load test, free vibration test, and forced vibration test are carried out, respectively. The test results show that the pipe pile has good deformation ability and damping characteristics.
The microbial-induced calcite precipitation is a common biomineralization process widespread in nature, which has been widely used in geotechnical engineering [7]. Studies have shown that MICP is an effective biological consolidation technique to improve the deformation resistance and enhance the impermeability of consolidated sand samples: DeJong et al. [8] studied the shear strength of the MICP consolidated sand samples; the test results show that the shear strength of the sand samples is significantly improved; Li et al. [9] found that MICP can reduce the porosity and permeability of consolidation sand samples and increase the unconfined compressive strength; Liu et al. [10] studied the dynamic characteristics of calcareous sand after MICP consolidation, and it is found that the dynamic shear stress ratio and the ability to resist deformation of calcareous sand after MICP consolidation are obviously improved.

At present, there are few reports on the use of MICP consolidated rubber sand. A single-axis or cyclic loading test of MICP consolidated rubber sand samples with different rubber particle content was carried out in this paper. The test results and microscopic analysis provide reference data for the application of MICP consolidated rubber sand. 


\section{Testing of Raw Materials and Methods}

2.1. Testing Raw Materials. The $\mathrm{CASO}^{+}$Urea Medium was used to activate Sporosarcina pasteurii, and the $\mathrm{pH}$ value of the medium was adjusted between 7.3 and 7.8 with sodium hydroxide standard solution, and the growth curve of Sporosarcina pasteurii in the medium was measured (Figure 1). As shown in Figure 1, OD600 bacterial concentration increased and finally reached a plateau with the increase of duration. There were $15 \mathrm{~g}$ casein peptone, $5 \mathrm{~g}$ soybean peptone, $20 \mathrm{~g}$ urea, and $15 \mathrm{~g}$ sodium chloride contained in each liter liquid medium.

The particle size range of standard sand is $0.08 \mathrm{~mm}-2 \mathrm{~mm}$ (Figure 2) and the rubber particle size is 400 mesh (Figure 3). The PVC tube is perforated with built-in gauze as the mold for the sample, while the mold specification is $\Phi 50 \mathrm{~mm} \times 110 \mathrm{~mm}$ (diameter $\times$ height) (Figure 4). The purpose of drilling PVC pipe is to ensure that the nutrient solution around the sample can flow freely into the sample and the gauze is to prevent the rubber sand from leaking out of the mold.

2.2. Test Methods. Taking standard sand $345 \mathrm{~g}$, rubber particles were weighed according to $0 \%, 1 \%$, and $3 \%$ of the standard sand quality in turn. The standard sand and rubber particles were mixed into three groups of rubber sand samples (Table 1). When mixing, the standard sand and rubber particles are evenly mixed by continuous mechanical stirring for $5 \mathrm{~min}$. Each rubber sand sample was injected with $45 \mathrm{~g}$ of Sporosarcina pasteurii liquid and put into the $\Phi 50 \mathrm{~mm} \times 110 \mathrm{~mm}$ mold in three layers.

The rubber sand mold was immersed in the consolidation nutrient solution for microbial consolidation, and the consolidation time was 7 days, with the oxygen continuously pumped into the nutrient solution during consolidation. There were $15 \mathrm{~g}$ ammonium chloride, $2 \mathrm{~g}$ sodium bicarbonate, $73.5 \mathrm{~g}$ calcium chloride, $30 \mathrm{~g}$ urea, $15 \mathrm{~g}$ casein peptone, and $5 \mathrm{~g}$ soybean peptone contained in each liter consolidation nutrient solution. The flow rate of oxygen pumped into the consolidated nutrient solution should be controlled between $1.2 \mathrm{l} / \mathrm{min}$ and $1.5 \mathrm{l} /$ min. After consolidation, the rubber sand sample is removed from the mold and dried to constant weight (Figure 5).

The consolidated rubber sand samples after drying were tested as follows: (1) physical properties test; (2) uniaxial, cyclic loading (Figure 6); (3) mechanical properties test.

\section{Test Results and Analysis}

3.1. Physical Performance Testing. The mass of calcium carbonate after consolidation of samples (1) (3) (Table 1, note 4 ) is $29.20 \mathrm{~g}, 29.98 \mathrm{~g}$, and $29.27 \mathrm{~g}$, while dry density increment (Table 1 , note 5) is $0.13 \mathrm{~g} / \mathrm{cm}^{3}, 0.14 \mathrm{~g} / \mathrm{cm}^{3}$, and $0.11 \mathrm{~g} / \mathrm{cm}^{3}$ in turn. It can be seen that rubber particles do not significantly affect the induction process of microorganisms, and the consolidation effect is only related to the amount of Sporosarcina pasteurii liquid injected.

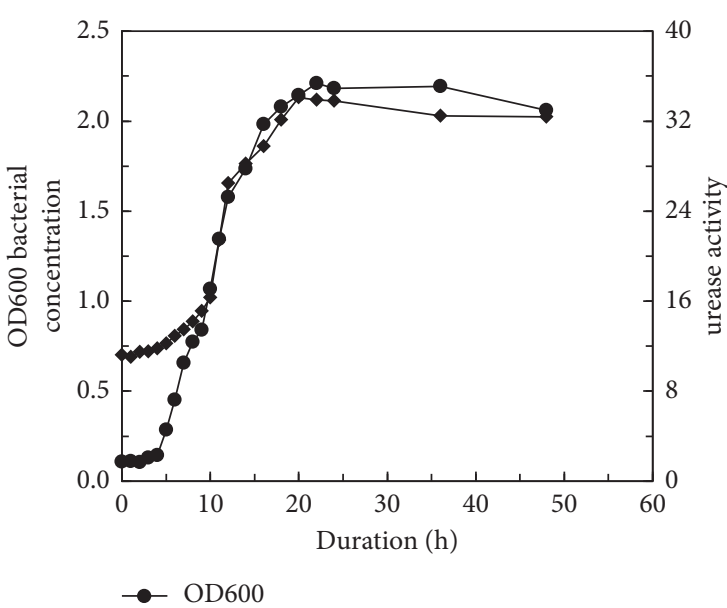

Figure 1: Growth curve of Sporosarcina pasteurii.

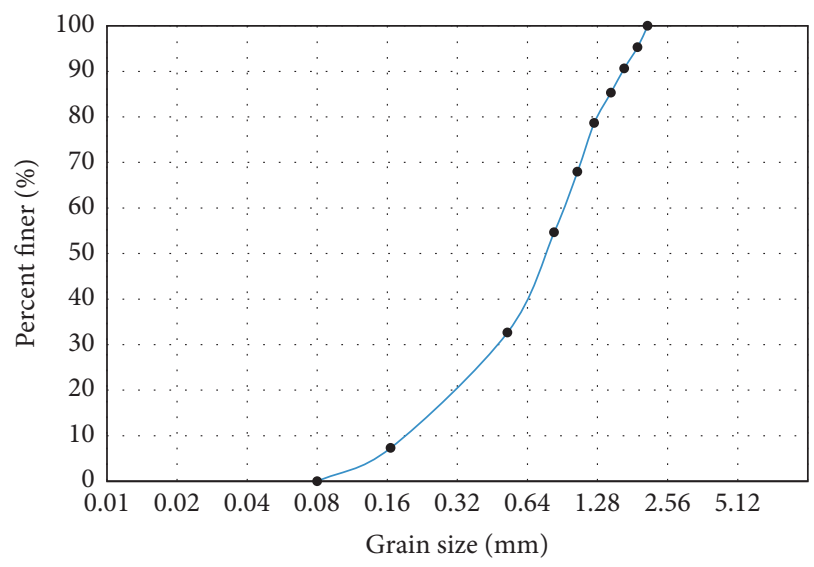

FIGURE 2: Standard sand gradation curve.

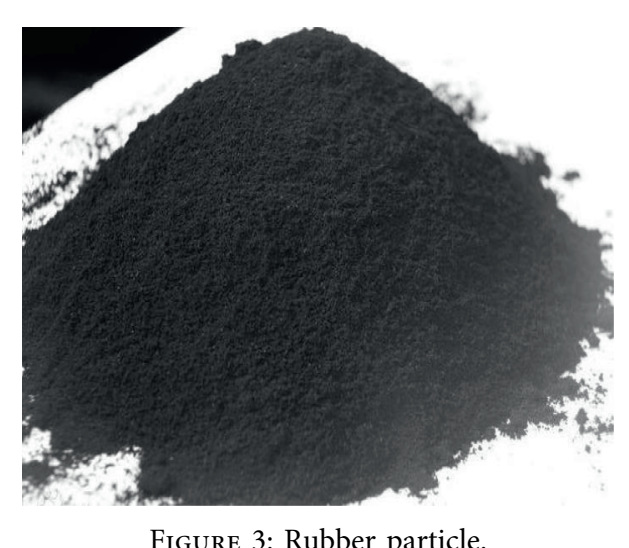

3.2. Uniaxial Compressive Strength Test. The uniaxial compressive strength of samples (1) (3) after consolidation is $183.44 \mathrm{kPa}, 223.17 \mathrm{kPa}$, and $216.34 \mathrm{kPa}$ in turn, and the limiting compressive strain is $0.21,0.20$, and 0.29 in turn, as shown in Figures 7 and 8 . It can be seen that the ultimate uniaxial compressive strength and ultimate compressive strain of rubber sand samples increase with the increase of rubber particle content after consolidation, which mean that 


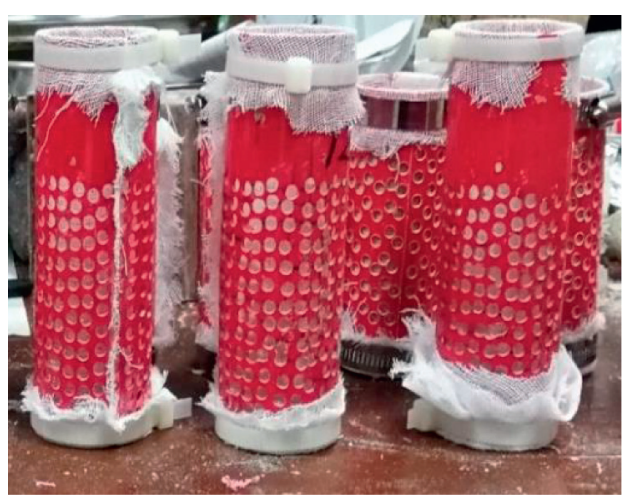

Figure 4: Test die.

TABLE 1: Sample parameters.

\begin{tabular}{lccccccc}
\hline & \multicolumn{3}{c}{ Before consolidation } \\
$\begin{array}{l}\text { Sample } \\
\text { number }\end{array}$ & $\begin{array}{c}\text { Standard } \\
\text { sand }(\mathrm{g})\end{array}$ & $\begin{array}{c}\text { Rubber } \\
\text { particles }(\mathrm{g})\end{array}$ & $\begin{array}{c}\text { Rubber } \\
\text { sand }(\mathrm{g})\end{array}$ & $\begin{array}{c}\text { Dry density of rubber } \\
\text { sand }\left(\mathrm{g} / \mathrm{cm}^{3}\right)\end{array}$ & $\begin{array}{c}\text { Bacterial liquid } \\
\text { quality }(\mathrm{g})\end{array}$ & $\begin{array}{c}\text { After consolidation } \\
\text { Rubber } \\
\text { sand }(\mathrm{g}) \\
\text { (6) }\end{array}$ & $\begin{array}{c}\text { Dry density of rubber } \\
\text { sand }\left(\mathrm{g} / \mathrm{cm}^{3}\right)\end{array}$ \\
\hline$(1)$ & $(2)$ & $(3)$ & $(4)$ & 45 & 374.20 & 1.73 \\
$(2)$ & 345 & 0 & 345.00 & 1.60 & 45 & 378.43 & 1.75 \\
$(3)$ & 345 & 3.45 & 348.45 & 1.61 & 45 & 384.62 & 1.76 \\
\hline
\end{tabular}

Note. (1) The data in the table are the average values of the three samples in the same group. The content of rubber particles is $0 \%, 1 \%$, and $3 \%$ of the standard sand. (3) (4) = (3)/( $\pi / 4 \times 52 \times 11)$; (7) = (6)/( $\pi / 4 \times 52 \times 11)$. (4) The quality of calcium carbonate after consolidation = (6) - (3). (5) The dry density increment of rubber sand after consolidation $=(7)-(4)$.

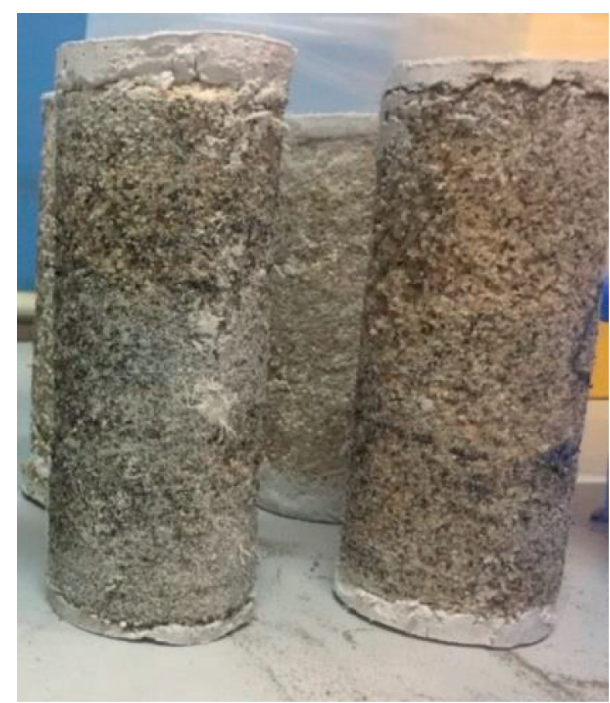

FIgURE 5: Sample of consolidated rubber sand.

rubber particles improve the compressive strength and deformation ability of consolidated rubber sand samples.

\subsection{Mechanical Performance Tests for Cyclic Loading}

3.3.1. Hysteresis Curves. Cyclic loading tests were carried out on the demolded and dried consolidated rubber sand samples by using a servo press (Figure 6), with a stress amplitude of $20-100 \mathrm{kPa}$, loading frequency is $0.1 \mathrm{~Hz}$, and

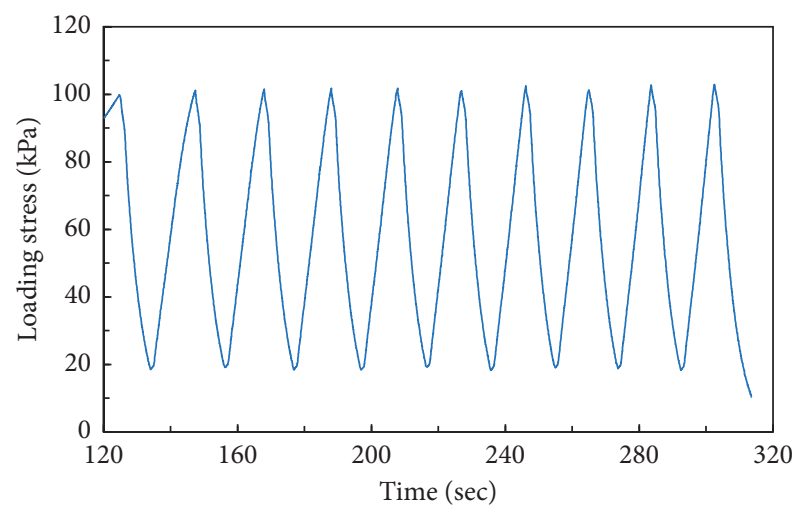

Figure 6: Cyclic loading system.

the number of loading and unloading cycles is 9. The hysteresis curve can be used to analyze the damping ratio, stiffness, and energy dissipation capacity of consolidated rubber sand samples with different rubber particle content. The schematic diagram of hysteresis loop analysis is shown in Figure 9; the damping ratio $\lambda$ and the hysteresis loop slope $\kappa$ are calculated by the following formulas:

$$
\begin{aligned}
& \lambda=\frac{A}{\left(4 \pi A_{s}\right)}, \\
& \kappa=\frac{\left(\sigma_{d \max }-\sigma_{d \min }\right)}{\left(\varepsilon_{d \max }-\varepsilon_{d \min }\right)},
\end{aligned}
$$




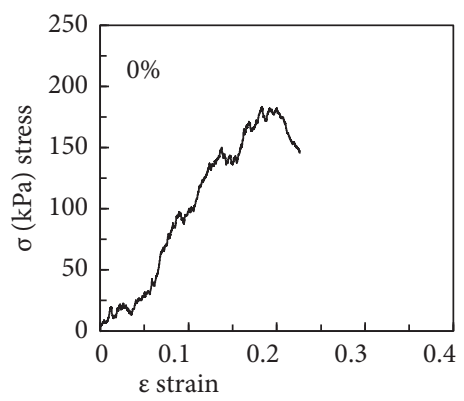

(a)

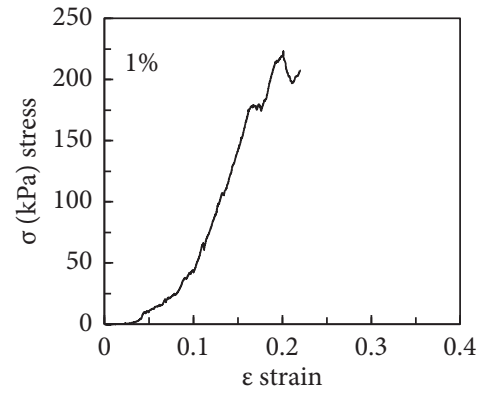

(b)

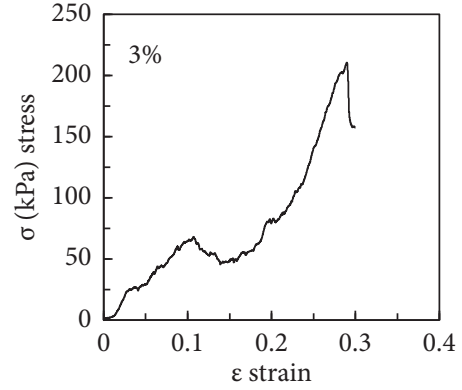

(c)

FIGURE 7: Stress-strain curves of bonded rubber sand samples.

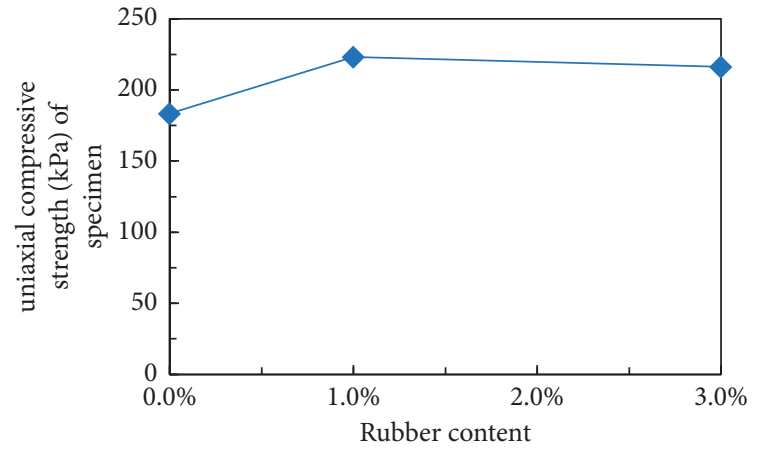

FIGURE 8: Effect of rubber particle content on uniaxial compressive strength of consolidated rubber sand samples.

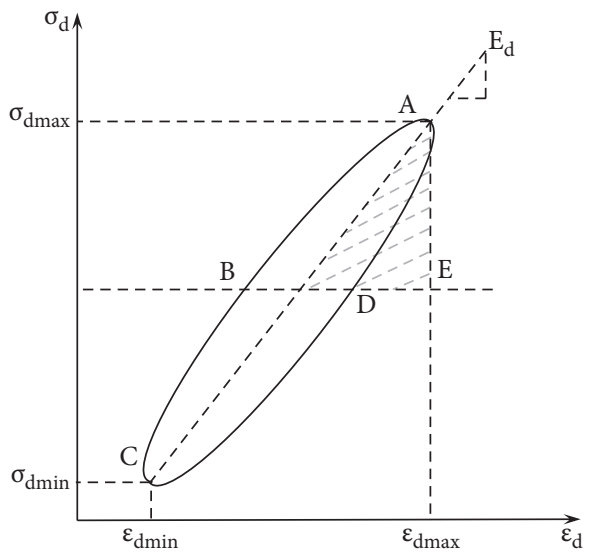

Figure 9: Calculation diagram of hysteresis loop.

where $A$ is the area of the hysteresis loop, reflecting the magnitude of the energy dissipated in a cycle period; $\mathrm{A}_{s}$ is the area of the triangle region AEF (Figure 9). The maximum and minimum dynamic stresses are $\sigma_{d \max }$ and $\sigma_{d \min }$, respectively; the maximum and minimum dynamic strains are $\varepsilon_{d \max }$ and $\varepsilon_{d \min }$, respectively.

The hysteresis curves of consolidated rubber sand samples with different rubber particle content are obtained by the test. As shown in Figure 10, the dynamic strains of the sample increase with the increase of rubber particle content.
3.3.2. Damping Ratio. The damping ratio curve of consolidated rubber sand samples with different rubber particle content is shown in Figure 11: with the increase of loading and unloading cycle, the irreparable plastic deformation of the sample becomes larger and larger, which leads to the decrease of damping ratio. The damping ratio of rubber particles with $3 \%$ is significantly higher than that of other two groups, which shows that the effect of rubber particles on the damping ratio of consolidated rubber sand is remarkable.

3.3.3. Hysteresis Loop Slope. The hysteresis loop slope $\kappa$ can reflect the stiffness of the consolidated rubber sand sample. The hysteresis loop slope of consolidated rubber sand samples with different rubber particle content is shown in Figure 12: with the increase of loading and unloading cycle times, the deformation ability of the sample becomes smaller and smaller, which leads to the increase of hysteresis loop slope. The slope of hysteresis loop increases gradually with the increase of rubber particle content, which indicates that the effect of rubber particles on the deformation resistance of consolidated rubber sand sample is significant.

3.3.4. Hysteresis Loop Area. The hysteresis loop area $A$ can reflect the energy dissipation capacity of consolidated rubber sand samples. The greater the $A$, the stronger the energy dissipation capacity of the samples. The hysteresis loop area of consolidated rubber sand samples with different rubber particle content is shown in Figure 13. As the number of loading and unloading cycles increases, the irreparable plastic deformation of the sample increases and the energy dissipation capacity of the sample becomes smaller and smaller. The energy dissipation capacity of the sample with $3 \%$ rubber sand particles is significantly higher than that of the other two groups, indicating that the effect of rubber particles on the energy dissipation capacity of consolidated rubber sand sample is significant.

\section{SEM Analysis of Bonded Rubber Sand Particles}

The SEM photographs of the consolidated rubber sand specimens after consolidation and drying (Figure 14) show 


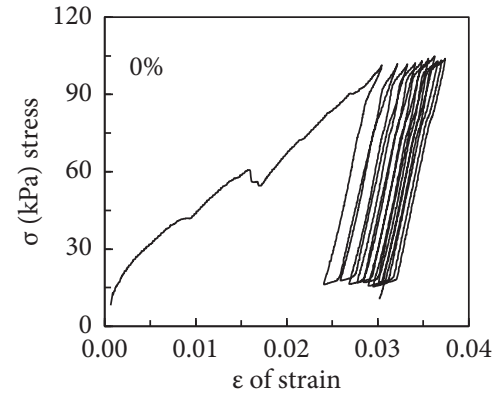

(a)

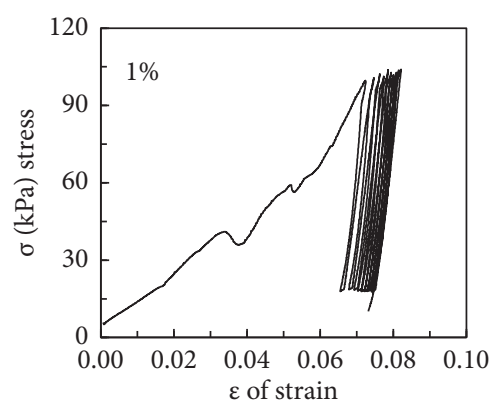

(b)

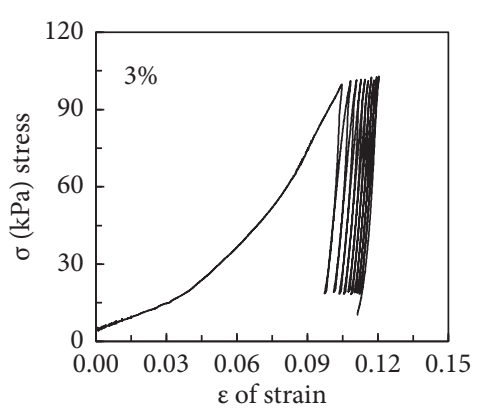

(c)

Figure 10: Effect of rubber particle content on hysteresis curve.

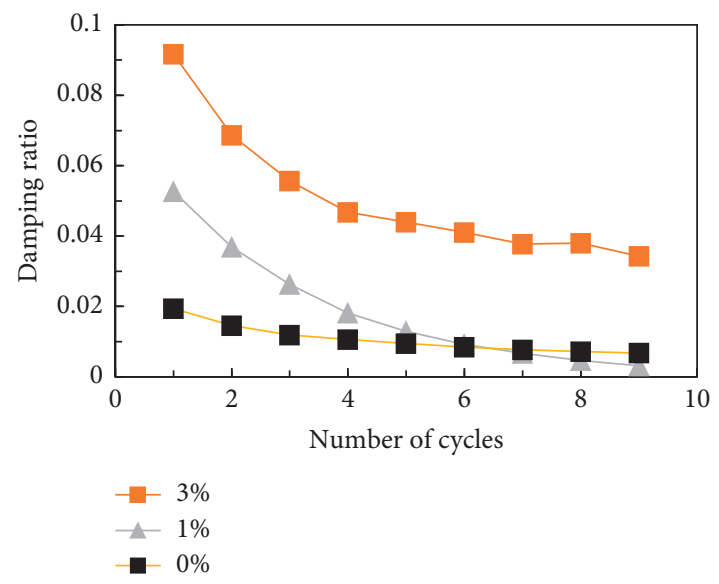

FIGURE 11: Effect of rubber particle content on damping ratio.

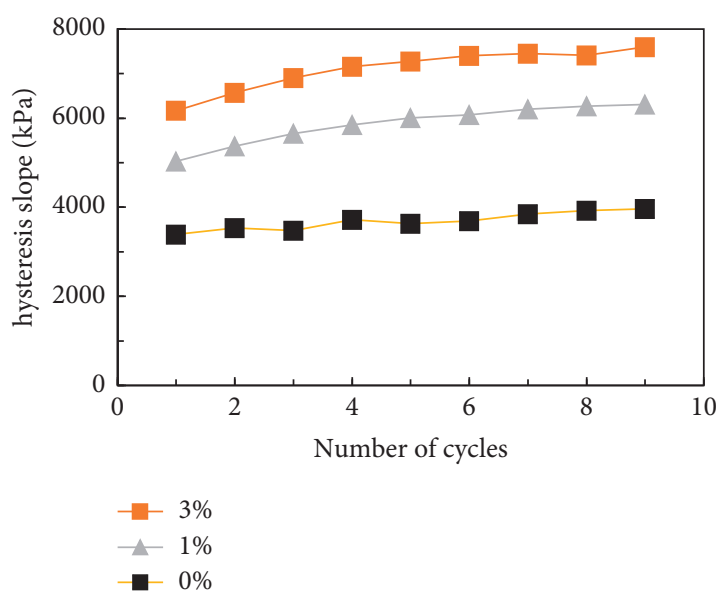

FIGURE 12: Effect of rubber particle content on the slope of hysteresis loop.

that the calcium carbonate crystals induced by Sporosarcina pasteurii adhere to the surface of sand particles and rubber particles, effectively filling the gap between sand particles and rubber particles, and solidifying sand particles and rubber particles into rubber sand consolidation body.

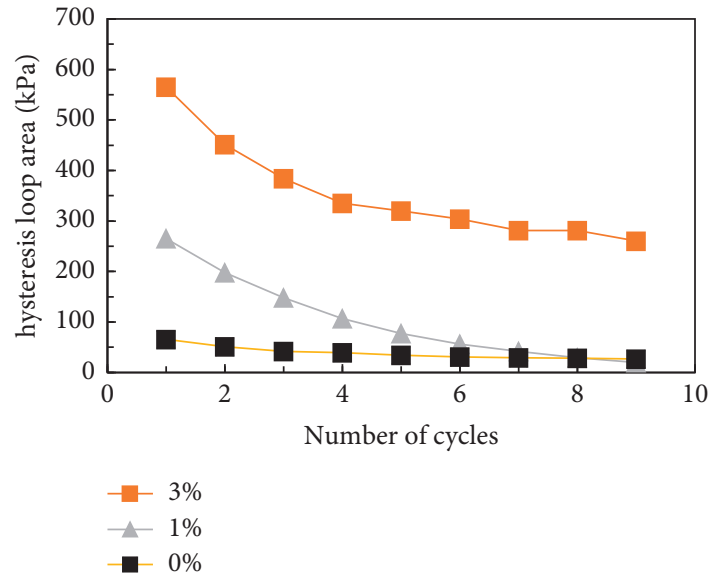

FIGURE 13: Effect of rubber particle content on hysteresis loop area.

In the rubber sand consolidation body, the sand particles are the skeleton of the consolidation body, rubber particles with honeycomb structure are filled between sand particles, and honeycomb structure absorbs external input energy through deformation. Therefore, more rubber particles can make the consolidated rubber sand sample have the ability to bear larger deformation, and larger deformation capacity means that the sample can consume more external input energy. Therefore, consolidated rubber sand is a good damping material.

\section{Discussion}

Sporosarcina pasteurii will produce urease in the metabolic process; the enzyme can decompose urea, forming $\mathrm{NH}^{+}$and $\mathrm{Ca}^{2+}$. When the solution contains a certain concentration of $\mathrm{Ca}^{2+}, \mathrm{Ca}^{2+}$ will be adsorbed by the cells. Then the calcium carbonate crystals are nucleated by the cells and grow under gelling effect around the bacteria. The growing calcium carbonate crystals will fill the gaps among the particles of standard sand and embedded rubber and furthermore will cement these particles.

The MICP process fills the gaps between the standard sands and solidifies them as a structural base with the embedded rubber particles. The composite crystalline form 

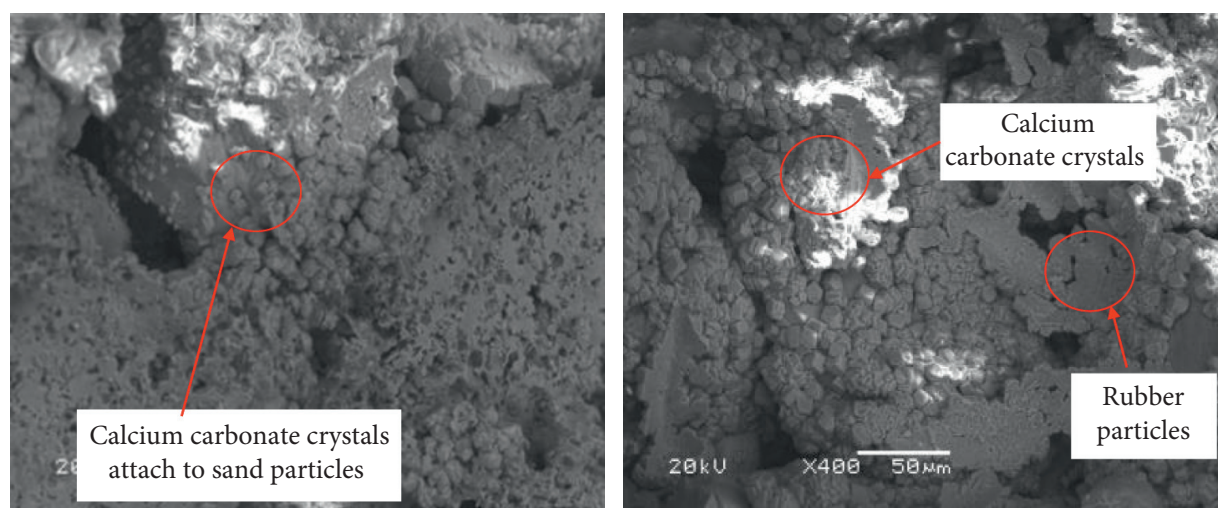

Figure 14: Photograph by electron microscope.

of calcium carbonate formed by the MICP process is very good at cementing the standard sand. The calcium carbonate in the form of composite crystals formed by the MICP process can well cement the pores between the standard sand and the foam particles, forming a homogeneous slab-like material with strength. The rubber is mixed into the standard sand. By using the consolidation of MICP, its filling effect and its own elastic behavior can improve the internal void structure of the material and effectively absorb the vibration energy. In Figure 14, the sand with strength formed by MICP is used as the base material. When vibration occurs, the macroscopically continuous vibration damping material will be microscopically affected by the stress or alternating stress to produce relative motion between molecules or lattices and plastic slip. When vibration occurs, the macroscopically continuous damping material will produce relative motion and plastic slip between molecules or lattices in the microscopic level due to stress or alternating stress, thus producing energy consumption. As a polymer, the relative motion between molecules can be easily generated. When rubber is added to the material, the relative motion and plastic slip between the rubber itself, rubber and other materials will be generated and can be greatly enhanced at the microscopic level, which increases the energy consumption of the material under vibration. The energy consumption of the material is increased under vibration, i.e., there is a large amount of damping, so as to obtain the vibration damping effect of the glued material.

\section{Conclusion}

In this paper, MICP was used to consolidate rubber sand with different rubber particle content. Based on the results of uniaxial and cyclic loading tests and SEM analysis, the conclusions are as follows:

(1) The precipitation process of calcium carbonate induced by microorganism is not affected by the amount of rubber particles, and the consolidation effect is only related to the amount of Sporosarcina pasteurii solution mixed in.

(2) Rubber particles improve the compressive strength and deformation ability of consolidated rubber sand samples and significantly enhance the damping ratio, resistance to deformation, and energy dissipation ability of consolidated rubber sand samples.

(3) MICP bonded the sand particles and rubber particles into rubber sand consolidation body. Because of the honeycomb structure characteristics of rubber particles, the consolidated rubber sand samples have the ability to withstand large deformation, which means that rubber sand is a good damping material.

\section{Data Availability}

None of the material in the paper has been published or is under consideration for publication elsewhere. The data used to support the findings of this study are included within the article.

\section{Conflicts of Interest}

The author declares no conflicts of interest or personal relationships that could have appeared to influence the work reported in this paper.

\section{References}

[1] G. Jian, Wu, and G. Hui, "Research progress in novel damping materials," Materials Reports, vol. 20, no. 12, pp. 53-56, 2006.

[2] J. Guo, X. Zeng, and Q. Luo, "Research progress of rubber damping materials," Special Purpose Rubber Products, vol. 28, no. 7, pp. 175-178, 2012.

[3] H. Hazarika, J. Otani, and Y. Kikuchi, "Evaluation of tyre products as ground improving geomaterials," Proceedings of the Institution of Civil Engineers - Ground Improvement, vol. 165, no. 4, pp. 267-282, 2012.

[4] M. Neaz Sheikh, M. S. Mashiri, J. S. Vinod, and H.-H. Tsang, "Shear and compressibility behavior of sand-tire crumb mixtures," Journal of Materials in Civil Engineering, vol. 25, no. 10, pp. 1366-1374, 2013.

[5] H.-H. Tsang, "Seismic isolation by rubber-soil mixtures for developing countries," Earthquake Engineering \& Structural Dynamics, vol. 37, no. 2, pp. 283-303, 2008.

[6] A. K. Panah and A. H. Khoshay, "A new seismic isolation system:sleeved-pile with soil-rubber mixture," International Journal of Civil Engineering,Transaction B:Geotechnical Engineering, vol. 13, no. 2, pp. 124-132, 2015. 
[7] Q. Chun-xiang, W. An-hui, and X. Wang, "Advances of soil improvement with bio-grouting," Rock and Soil Mechanics, vol. 36, no. 6, pp. 1537-1548, 2015.

[8] J. T. Dejong, M. B. Fritzges, and K. Nüsslein, "Microbially induced cementation to control sand response to undrained shear," Journal of Geotechnical and Geoenvironmental Engineering, vol. 132, no. 11, pp. 1381-1392, 2006.

[9] D. Li, K.-L. Tian, H.-L. Zhang et al., "Experimental investigation of solidifying desert aeolian sand using microbially induced calcite precipitation," Construction and Building Materials, vol. 172, pp. 251-262, 2018.

[10] H. Liu, P. Xiao, X. Yang et al., "Dynamic behaviors of MICPtreated calcareous sand in cyclic tests," Chinese Journal of Geotechnical Engineering, vol. 40, no. 1, pp. 38-45, 2018. 